\title{
STUDY OF PATIENTS PRESENTING WITH HAEMOPTYSIS TO TERTIARY CARE CENTRE
}

\author{
Ramakrishna Rachakonda ${ }^{1}$, D. V. C. Nagasree ${ }^{2}$, Kalyankumar P. V3
}

1 Professor and HOD, Department of Pulmonology, Katuri Medical College, Guntur.

${ }^{2}$ Associate Professor, Department of Ophthalmology, Katuri Medical College, Guntur.

${ }^{3}$ Associate Professor, Department of Pulmonology, Katuri Medical College, Guntur.

\section{ABSTRACT}

\section{BACKGROUND}

Context- We have chosen 216 patients presenting with a chief complaint of haemoptysis attending our tertiary care unit both mild, moderate and severe in our prospective study from 2013 to 2016.

Aim- To study patients of haemoptysis including their age, sex distribution, background disease, severity of haemoptysis, smoking status, active disease existing and method of treatment.

Settings and Design- We have taken up patients with the complaint of haemoptysis analysed history and did thorough Physical examination.

\section{MATERIALS AND METHODS}

A total of 216 patients presented with haemoptysis above 20 years of age were included in our study. Investigated these patie nts with chest x-ray and sputum for AFB. CT scan chest, bronchoscopy were done in selective patients. Smoking history was taken from all the patients, both male and female after taking consent from the Ethical Committee. Majority of the patients were subjected to conservative management. Glue therapy and Bronchial artery embolisation were required for 6 patients.

\section{RESULTS}

Among 216 patients admitted in the prospective study, maximum number of patients were seen in 30 - 49 years' group. Males outnumbered females in our study. Pulmonary tuberculosis both acute and old inactive tuberculous residual lesions are responsible for haemoptysis in nearly $60 \%$ of patients; $9.2 \%$ cases had bronchiectasis. Nearly $10 \%$ of patients came for streaky haemoptysis secondary to acute pharyngitis. Iatrogenic haemoptysis secondary to pulmonary procedures occurred in $3.24 \%$. Post bronchoscopy procedures are an important cause of significant haemoptysis in $6.10 \%$. Post procedural haemoptysis was always self-limiting and never life-threatening in our study. Among TB patients, active tuberculosis is responsible for haemoptysis in $25.92 \%$ among new cases of TB, followed by old inactive TB (19.9\%), Defaulters (9.72\%), Relapse after successful treatment (3.24\%) and MDR TB (0.92\%). Haemoptysis in our study group was mild in a majority (< $100 \mathrm{~mL} /$ day), moderate $(100-300$ $\mathrm{mL} /$ day) in only 9 patients and severe ( $>300 \mathrm{~mL} /$ day) in only 4 patients. Most of the patients were managed only conservatively. Only six patients required intervention in the form of cyanoacrylate glue bronchoscopically and only three patients were subjected to bronchial artery embolism.

\section{CONCLUSION}

Haemoptysis is an alarming symptom both to the patient and the physician. Tuberculosis old and active is an important cause of haemoptysis in India. URTI, acute pharyngitis, bronchiectasis, chronic bronchitis and lung tumours and cancer are important causes of haemoptysis. Haemoptysis is mild in a large number of patients. Glue therapy and bronchial artery embolisation were required for 6 patients. Majority of the patients were managed conservatively; 10\% required ICU admission.

\section{KEYWORDS}

Haemoptysis, Tuberculosis, Pharyngitis, Bronchiectasis, Bronchoscopy, Pulmonary Thromboembolism.

HOW TO CITE THIS ARTICLE: Rachakonda R, Nagasree DVC, Kalyankumar PV. Study of patients presenting with haemoptysis to tertiary care centre. J. Evolution Med. Dent. Sci. 2017;6(25):2105-2108, DOI: 10.14260/Jemds/2017/458

\section{BACKGROUND}

Haemoptysis is a very common presentation in the respiratory outpatient department. This symptom is viewed seriously both by the Physician and the patient. From the patient's point of view, it is alarming as it indicates a serious respiratory illness.

Financial or Other, Competing Interest: None.

Submission 20-02-2017, Peer Review 16-03-2017,

Acceptance 22-03-2017, Published 27-03-2017.

Corresponding Author:

Dr. Ramakrishna Rachakonda,

Sanjeevani Hospital,

A1, Ramkuteer Majestic,

3/13, Brodipet, Guntur.

E-mail: ramakrishna45@yahoo.co.in

DOI: $10.14260 /$ jemds $/ 2017 / 458$
From the Physician's standpoint haemoptysis makes him alert to diagnose exact cause and deliver the treatment and allay the fear of the patient. Haemoptysis can occur from a wide range of conditions. From very trivial to very serious.

Causes of haemoptysis include Tracheobronchial source: Neoplasm (bronchogenic carcinoma, endobronchial metastatic tumour, Kaposi's sarcoma, bronchial carcinoid), Bronchiectasis, Broncholithiasis, Airway trauma and Foreign body Pulmonary parenchymal source: Lung abscess, Pneumonia, Tuberculosis, Mycetoma ('fungus ball') Goodpasture's syndrome, Idiopathic pulmonary haemosiderosis, Wegener's granulomatosis, Lupus pneumonitis, Lung contusion, Primary vascular source, Arteriovenous malformation and Pulmonary embolism.

Haemoptysis can occur in Elevated pulmonary venous pressure (mitral stenosis), Pulmonary artery rupture 
secondary to balloon-tip pulmonary artery catheter manipulation. Miscellaneous/rare causes include Pulmonary endometriosis, Systemic coagulopathy or use of anticoagulants or thrombolytic agents. Majority of our patients of serious haemoptysis have Tuberculosis as the cause, both active and inactive followed by Bronchiectasis. The Physician should consider appropriate cause basing on clinical examination, Chest x-ray, ECG, CT scan of chest and systemic examination along with other appropriate investigations. Identification of the cause of haemoptysis and localisation of the site and the appropriate vessel can help us in alleviating the suffering of the patient.

Haemoptysis whatever be the quantity is a challenge to the Physician, because even a small quantity can choke up the respiratory tract and kill a patient. Appropriate guidelines for the management of haemoptysis include admission into the Hospital, maintenance of airway and keeping the patient on the side of the lung causing the haemoptysis, cough suppressants and appropriate sedatives can prevent further haemoptysis. Appropriate measures should be taken if systemic bleeding tendency is the cause of haemoptysis. Adequate oxygenation should be ensured. The site of haemoptysis can be observed by bronchoscopy and appropriate measures like cold saline administration or even glue therapy can be administered. Multi-Detector CT angiography (MDCTA) can help in detecting the site of the lesion and can supplement bronchoscopy. Bronchial artery embolisation after catheterisation is a recent technique using Gelatin sponge or Polyvinyl alcohol particles. Surgical therapy involving Lobectomy or Pneumonectomy can be the last option for saving the patient carrying a high mortality rate.

\section{MATERIALS AND METHODS}

We have admitted 216 patients in our study who presented with symptom of haemoptysis of different degree. Here, we have made an attempt to classify different causes of haemoptysis; classified into mild, moderate and severe. Studied their age and sex and the type of disease underneath. We studied the treatment outcome and compared our results with other studies on similar subject. We classified haemoptysis as mild when expectorated blood/24 hours was less than $100 \mathrm{~mL}$, moderate when blood spat was between 100 to $300 \mathrm{~mL}$ and severe when it was more than 300 .

\section{RESULTS}

Predominant number of patients in our study fall in the above thirty age group. Maximum incidence is seen in 40 - 49 years' age group. Majority of our patients are male (90.27\%). Females constitute the rest $(9.73 \%)$.

Aetiology of haemoptysis: Pulmonary tuberculosis active or inactive is the commonest cause occurring in $59.72 \%$. This is followed by URTI and acute pharyngitis in $10.18 \%$. Severe pharyngitis leads to congestion of pharynx and may lead to streaky haemoptysis. Patients seek medical attention because of the fear of a serious disease inside. In our study, it is never alarming and all the patients recovered with antibiotic therapy. Third important cause is bronchiectasis accounting for $9.72 \%$ of patients. Lung tumours caused haemoptysis in $4.17 \%$ of our study group.

\section{Haemoptysis among TB Patients}

New cases of TB accounted for $56 \%$ among the TB group. Old inactive TB is the cause of haemoptysis in $33.33 \%$, Defaulters $16.28 \%$, Relapse patients $5.43 \%$ and MDR TB $1.55 \%$ in the TB group. All but one patient had mild haemoptysis. One patient had moderate haemoptysis secondary to bronchial adenoma in the form of a pedunculated mass at the carina and was managed conservatively, but lost to followup.

Bronchiectasis is an important cause of haemoptysis in < $10 \%$ cases of haemoptysis. Two thirds of the cases of haemoptysis in the bronchiectasis group gave history of treated pulmonary TB. Pulmonary tumours both benign and malignant including pulmonary secondaries caused haemoptysis in $4.17 \%$ of cases.

\section{Severity of Haemoptysis and Management in our Study}

Haemoptysis was mild in >93\%. Moderate in $4.16 \%$ and severe in $1.85 \%$. All the patients in the mild group and some in the moderate group were managed conservatively. We attempted cyanoacrylic glue therapy in three patients through bronchoscopy. Two patients remained symptom free for six months. One came for recurrence of haemoptysis in 15 days. Bronchial artery embolisation was done in three patients of severe haemoptysis with the help of Department of Cardiology. One of these patients came for recurrence in two weeks. Most of the cases of moderate and severe haemoptysis were from Tuberculosis group.

In our study, around 21 patients (10\%) required ICU admission. None of the patients required ventilator treatment. We managed most of them conservatively. We did not opt for surgery among our patients studied.

\begin{tabular}{|c|c|c|c|}
\hline Sl. No. & Age Group & No. of Patients & Percentage \\
\hline 1. & $21-30$ & 26 & $12.03 \%$ \\
\hline 2. & $30-39$ & 54 & $25 \%$ \\
\hline 3. & $40-49$ & 77 & $35.64 \%$ \\
\hline 4. & $50-59$ & 47 & 21.75 \\
\hline 5. & $>60$ & 12 & $5.55 \%$ \\
\hline \multicolumn{3}{|c|}{ Table 1. Age Distribution of Cases of Haemoptysis } \\
\hline
\end{tabular}

\begin{tabular}{|c|c|c|c|}
\hline Type & No. Males \% & No. Females \% & Total \\
\hline Mild & 185 & 18 & 203 \\
\hline Moderate & 07 & 02 & 09 \\
\hline Severe & 03 & 01 & 04 \\
\hline Total & $\mathbf{1 9 5 ( 9 0 . 2 7 \% )}$ & $\mathbf{2 1}(\mathbf{9 . 7 2 \% )}$ & $\mathbf{2 1 6}(\mathbf{1 0 0 \% )}$ \\
\hline \multicolumn{4}{|c}{ Table 2. Sex Distribution of Cases of Haemoptysis } \\
\hline
\end{tabular}

\begin{tabular}{|c|c|c|c|}
\hline Sl. No. & Cause & No. of Patients & \% \\
\hline 1. & $\begin{array}{c}\text { URTI Acute } \\
\text { Pharyngitis }\end{array}$ & 22 & $10.18 \%$ \\
\hline 2. & PTB & 129 & $59.72 \%$ \\
\hline 3. & Bronchiectasis & 21 & $9.72 \%$ \\
\hline 4. & Chronic Bronchitis & 07 & $3.24 \%$ \\
\hline 5. & $\begin{array}{c}\text { Post Bronchoscopy } \\
\text { and Iatrogenic }\end{array}$ & 13 & $6.10 \%$ \\
\hline 6. & Pneumonias & 04 & $1.85 \%$ \\
\hline 7. & Lung Abscess & 04 & $1.85 \%$ \\
\hline 8. & Aspergilloma & 03 & 1.39 \\
\hline 9. & $\begin{array}{c}\text { Mitral Heart Disease } \\
\text { or Pulmonary } \\
\text { Oedema }\end{array}$ & 02 & $0.93 \%$ \\
\hline 10. & $\begin{array}{c}\text { Pulmonary } \\
\text { Thromboembolism }\end{array}$ & 02 & $0.93 \%$ \\
\hline 11. & $\begin{array}{c}\text { Lung Cancer and } \\
\text { Lung Tumours }\end{array}$ & 09 & $4.17 \%$ \\
\hline 12. & Unknown Cause & 02 & $0.93 \%$ \\
\hline \multicolumn{3}{|c|}{ Table 3. Aetiology of Haemoptysis } \\
\hline
\end{tabular}




\begin{tabular}{|c|c|c|c|}
\hline $\begin{array}{c}\text { Sl. } \\
\text { No. }\end{array}$ & Type of TB & $\begin{array}{c}\text { No. of Cases \% } \\
\text { in TB Group }\end{array}$ & $\begin{array}{c}\text { Percentage in } \\
\text { the Total }\end{array}$ \\
\hline 1. & New Cases of TB & $\begin{array}{c}56(43.41 \% \text { in TB } \\
\text { Group) }\end{array}$ & $25.92 \%$ \\
\hline 2. & Old Inactive TB & $43(33.33 \%)$ & $19.90 \%$ \\
\hline 3. & Defaulter & $21(16.28 \%)$ & $9.72 \%$ \\
\hline 4. & Relapse & $07(5.43 \%)$ & $3.24 \%$ \\
\hline 5. & MDR & $02(1.55 \%)$ & $0.92 \%$ \\
\hline \multicolumn{3}{|c|}{ Table 4. Haemoptysis among TB Patients } \\
\hline
\end{tabular}

\begin{tabular}{|c|c|c|c|}
\hline Sl. No. & Type of Haemoptysis & No. of Patients & $\mathbf{\%}$ \\
\hline 1. & Mild & 203 & $93.98 \%$ \\
\hline 2. & Moderate & 09 & $4.16 \%$ \\
\hline 3. & Severe & 04 & $1.85 \%$ \\
\hline \multicolumn{3}{|c|}{ Table 5. Severity of Haemoptysis } \\
\hline
\end{tabular}

\begin{tabular}{|c|c|c|c|}
\hline Sl. No. & Type of Tumour & No. of Cases & Percentage \\
\hline 1. & Benign tumour & 1 & $11.1 \%$ \\
\hline 2. & Malignant Primary & 7 & $77.78 \%$ \\
\hline 3. & $\begin{array}{c}\text { Malignant } \\
\text { Secondary }\end{array}$ & 1 & $11.11 \%$ \\
\hline \multicolumn{3}{|c|}{ Table 6. Haemoptysis in Lung Tumours- Total No. } \\
of Cases 9 (4.16\%) \\
\hline
\end{tabular}

\begin{tabular}{|c|c|c|c|}
\hline Sl. No. & Type of Bronchiectasis & No. of Patients & \% \\
\hline 1. & Congenital & 05 & $23.80 \%$ \\
\hline 2. & Post Tubercular & 14 & $66.67 \%$ \\
\hline 3. & Unknown aetiology & 02 & $9.52 \%$ \\
\hline 4. & Unilateral & 16 & $76.19 \%$ \\
\hline 5. & Bilateral & 05 & $23.80 \%$ \\
\hline 6. & $\begin{array}{c}\text { Pleuro-Pulmonary } \\
\text { Fibrosis Left }\end{array}$ & 02 & $9.52 \%$ \\
\hline \multicolumn{3}{|c|}{ Table 7. Haemoptysis among Bronchiectasis Patients- } \\
Total No. 21 (9.72\%) \\
\hline
\end{tabular}

\begin{tabular}{|c|c|c|c|c|}
\hline $\begin{array}{c}\text { Type of } \\
\text { Haemoptysis }\end{array}$ & Conservative & $\begin{array}{c}\text { Glue } \\
\text { Therapy }\end{array}$ & $\begin{array}{c}\text { Bronchial } \\
\text { Artery } \\
\text { Embolisation }\end{array}$ & $\begin{array}{c}\text { Total } \\
\text { No. }\end{array}$ \\
\hline Mild & 203 & 0 & 0 & 203 \\
\hline Moderate & 06 & 03 & & 09 \\
\hline Severe & & 00 & 03 & 03 \\
\hline Management & $209(96.75 \%)$ & $3(1.38 \%)$ & $3(1.38 \%)$ & \\
\hline \multicolumn{5}{|c|}{ Table 8. Methods of Management } \\
\hline
\end{tabular}

Among patients of mild haemoptysis, 13 patients came for followup with symptoms of haemoptysis.

\begin{tabular}{|c|c|c|c|}
\hline Sl. No. & $\begin{array}{c}\text { Category of } \\
\text { Haemoptysis }\end{array}$ & No. Patients & Recurrence \\
\hline 1. & Mild & 213 & 13 \\
\hline 2. & Moderate & 9 & 01 in 15 days \\
\hline 3. & Severe & 03 & 01 in 15 days \\
\hline \multicolumn{3}{|c|}{ Table 9. Recurrence of Haemoptysis } \\
\hline
\end{tabular}

\begin{tabular}{|c|c|c|}
\hline & No. of Patients & Percentage \\
\hline Smokers & 98 & $45.37 \%$ \\
\hline Ex-smokers & 58 & $26.85 \%$ \\
\hline Non-smokers & 60 & $27.77 \%$ \\
\hline Total & $\mathbf{2 1 6}$ & $\mathbf{1 0 0}$ \\
\hline Table 10. Smoking Status among Patients of Haemoptysis \\
\hline
\end{tabular}

\section{DISCUSSION}

Tuberculosis and Bronchiectasis are leading cause of haemoptysis in our study. The same view is endorsed in several other studies. $(1,2,3,4,5,6,7,8,9,10)$ Like in several studies, we had a male preponderance among the patients presenting with haemoptysis. Shantikumar Singh et al(11) found Paragonimiasis as an important cause of haemoptysis in North-East India. ${ }^{2}$ Bhatta DR et al found $6.5 \%$ cases of Pneumonia among cases of Haemoptysis.(2) Haemoptysis of different aetiologies can be found with normal x-ray.(12) European study from Portugal had bronchiectasis and congenital cardiopathy as causes of haemoptysis.(13) Though Tuberculosis is an important aetiology active, TB requiring anti-TB treatment is not always required.(3,12) Most of the patients of Haemoptysis in our study are from 30 - 50 years' group. Similar observation was seen in other studies.(6) Haemoptysis was seen more among smokers and ex-smokers in our study. Similar observation was seen in Subodh K Naval study.(6) Studies from Western world showed nontuberculous causes as aetiology.(7) Malignancy is an important aetiology in several studies. Other non-tuberculous causes should be identified in a case of haemoptysis even in Indian setting. ${ }^{8}$

Cyanoacrylic glue was administered bronchoscopically in our study. Mild haemoptysis is self-limiting in most of the cases and can be managed on an outpatient basis. Rakesh Chawla et al(13) used bronchoscopically cyanoacrylic glue in controlling haemoptysis in stable patients with success.

Bronchial artery embolism is an accepted method of treatment. It is necessary to embolise bronchial artery as well as non-bronchial systemic arteries.(14,15,16,17,18,19) Our experience in glue treatment and Bronchial Artery Embolisation is limited, nevertheless we initiated in selective patients.

The author with his experience feels that massive haemoptysis from tubercular aetiology is seen less frequently compared to the situation in India three decades ago. This is probably because of universal availability of Antituberculosis therapy and RNTCP programme enabling the patient to have ATT early and better awareness. Bronchiectasis and Aspergilloma are important causes of massive haemoptysis. Pulmonary tumour associated haemoptysis is mild in all the cases in our study.

\section{CONCLUSION}

Haemoptysis is an alarming symptom both to the patient and the Physician. Tuberculosis old and active is an important cause of haemoptysis in India. It should not be assumed always that it is because of Tuberculosis. Active investigation with all the parameters available should be done for proper diagnosis. Majority of the patients have mild haemoptysis. Endobronchial glue therapy and Bronchial Artery Embolisation (BAE) are evolving with development of bronchoscopy and catheterisation lab with trained cardiologists and they can be utilised in selective patients.

\section{Abbreviations}

BAE: Bronchial Artery Embolisation, MDCTA: Multi-Detector CT Angiography, ICU: Intensive Care Unit, CT: Computerised Tomography.

\section{REFERENCES}

[1] Abal AT, Nair PC, Cherian J. Haemoptysis: aetiology, evaluation and outcome-a prospective study in a thirdworld country. Respir Med 2001;95(7):548-52. 
[2] Bhatta DR, Singh TSK, Gokhale S. Hemoptysis: is it tuberculosis? (Nepal Study). Int J Infect Microbiol 2012;1(2):63-7.

[3] Rao DP, Reddy RN, Padmaja A. Aetiology of Haemoptysis: study in a medical college. International Journal of Current Medical and Applied Sciences 2015;8(1):24-6.

[4] Patel KR, Patel AK, Godhania N. Evaluation of patients with haemoptysis attending the chest clinic of tertiary referral hospital. Int J Res Med 2015;4(2):91-3.

[5] Rahman MK, Khan MMR, Tarik MH, et al. Etiological pattern of hemoptysis in tertiary level hospital in Bangladesh. TAJ 2009;22(1).

[6] Nawal SK, Heda MR. Haemoptysis: a prospective analysis of 110 cases. Asian Journal of Biomedical and Pharmaceutical Sciences 2013;3(21):1-3.

[7] Prasad R, Garg R, Singhal S, et al. Lessons from patients with hemoptysis attending a chest clinic in India. Ann Thorac Med 2009;4(1):10-2.

[8] Kumar A, Gupta AK, Gautam AK, et al. Not all hemoptysis is uberculosis-think of other etiologies. A lesson from a chest clinic in a rural tertiary care center in central India. International Journal of Medical Science and Public Health 2016;5(8):62-4.

[9] Ashraf 0. Hemoptysis, a developing world perspective. BMC Pulmonary Medicine 2006;6:1.

[10] Talwar D, Chudiwal J, Jain RC, et al. Hemoptysis: causes, interventions and outcomes - Indian single centre experience, European Respiratory Journal 2012;40(Suppl 56):P3491.

[11] Singh TS, Sugiyama H, Rangsiruji A. Paragonimus \& paragonimiasis in India. Indian $\mathrm{J}$ Med Res 2012;136(2):192-204.
[12] Sood R, Mukhopadhyaya S. Approach to a patient with haemoptysis and normal chest X-Ray. JIACM 2002;3(1):14-22.

[13] Pires FS, Teixeira N, Coelho F, et al. Hemoptysis etiology, evaluation and treatment in a university hospital. Rev Port Pneumol 2011;17(1):7-14.

[14] Chawla RK, Madan A, Mehta D, et al. Glue therapy in hemoptysis: a new technique. Lung India 2012;29(3): 293-4.

[15] Krishna VSVN, Atluri M, Kumar BK. Role of bronchial artery embolization in hemoptysis. IOSR Journal of Dental and Medical Sciences (IOSR-JDMS) 2016;15(4):21-30. Ver. ll.

[16] Singhal S, Banode P. Bronchial artery embolization in patients presenting with massive hemoptysis: initial experience from a rural tertiary centre of Central India. ISRN Pulmonology Article ID 601567 2011;2011: p. 5.

[17] Narasimhalu N, Sarkar M, Bhardwaj R, et al. Role of bronchial artery embolization in the management of hemoptysis. National Journal of Medical Research 2015;5(3):179-84.

[18] Gokhroo RK, Gupta R, Padmanabhan D, et al. Bronchial artery embolization for the treatment of haemoptysis: an experience with 20 patients. Indian J Cardiol 2013;16(3-4):5-8.

[19] Anuradha C, Shyamkumar NK, Vinu M, et al. Outcomes of bronchial artery embolization for life-threatening hemoptysis due to tuberculosis and post-tuberculosis sequelae. Diagn Interv Radiol 2012;18(1):96-101. 